\title{
Development of a Prototype for Measurement of Electrical Energy
}

\author{
Alysson Costa ${ }^{1 *}$, Fernanda Ciniello ${ }^{1}$, Gustavo Grzybowsk ${ }^{\mathbf{1}}$, Roberto C. Betini ${ }^{\mathbf{1}}$ \\ ${ }^{1}$ Universidade Tecnológica Federal do Paraná, Curitiba, Paraná, Brasil.
}

\begin{abstract}
The present work presents the development of a system of measurement of electric energy consumption. This system shows the consumer the amount of energy consumed and its respective monetary value in real time. The prototype was used in a case study to validate its operation. Data were collected to discuss the results obtained. In order to verify if the results obtained in the prototype were correct, several measurements of energy consumption were made in different residential equipment. The consumption values measured by the prototype were compared with the values obtained by the certified and calibrated energy meter provided by COPEL and were satisfactory.
\end{abstract}

Keywords: Meter of energy, consumption, electric energy, energy efficiency.

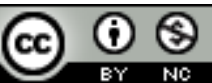

*Author of correspondence: alyssonpercicotty@gmail.com 


\section{INTRODUCTION}

Since the use of electricity as an energy source started, its production has experienced a frantic growth. This growth generates demand for the construction or expansion of new electric energy sources, increasing the environmental impact. Therefore, it is convenient to use energy efficiently. Monica Menkes ${ }^{1}$ argues that most authors dealing with energy efficiency issues point to these actions as one of the key instruments for reducing environmental impacts. Others argue that the type and application of energy efficiency techniques can contribute to sustainable development goals. According to the history of energy consumption provided by the "Empresa de Pesquisa Energética" (EPE), the consumption of the residential sector in Brazil accounted for 35\% of total consumption in 2015 i.e. $131 \mathrm{MWh}^{2}$.

Even being a responsible residential consumer, one hardly knows how much s/he is spending in just one hour leaving lights on, watching television, leaving equipment in the "stand by" among other activities run by electricity. Energy consumption is not seen as a real-time expense, let alone environmental impact. Due to lack of awareness and concern about this issue, efficient consumption seems to be a difficult goal to achieve. Sight is one of the five senses that allow living beings to improve the perception of the world. And it is through the sight that we will make the user aware of the benefits of consuming energy more efficiently. The proposed system presents in a display, technical and financial information of the consumption of electricity in real time.

Systems (already in existence), known as Home Energy Monitors, execute the monitoring in real time. The prototype to be developed aims to reduce implementation costs in relation to those available in the market. Also, the proposed mechanism must adapt to the operation of the Brazilian tariff system, have a simple operation and installation, and present a friendly interface with the necessary information.

The present work aims at the development of a system of measurement of electric energy consumption in the residential sector that presents the value in Brazilian Real $(\mathrm{R} \$)$ to the consumer, based on the national tariff system, in real time.

\section{MATERIAL AND METHODS}

\section{Arguments}

The implementation of smart grids makes it possible, among other things, to optimize and make the energy supply safer, to quickly rebuild the electrical system in case of interruptions, to enable the generation distributed by renewable sources, to stimulate the use of electric vehicles. Also, it is possible to measure energy, water and gas consumption at a distance, monitoring users' energy consumption, identifying energy loss points, testing applications and services for smart cities ${ }^{3}$.

Intelligent metering can help reduce waste in the residential sector. For this to be possible, it is necessary for consumers to have easy access to the available technologies by monitoring the individual consumption of each electrical device in their residence showing in monetary form how much each element of the residential electrical system consumes in a certain range of time.

Currently measurement systems are limited in terms of the quantity and quality of information that can be measured at a particular point in the residence. In addition, the integration between different systems within the residence is also complex, making the work challenging. There are several technologies available for this purpose on the market, but they still have a high cost which is not as attractive to residential consumer, since energy saving depends on the consumer's awareness. The existing meters in the Brazilian market have a price ranging from $\mathrm{R} \$ 120.00$, with the most expensive ones 
costing up to $\mathrm{R} \$ 1000.00$. This variation depends on the features of the meter and how one can perform the measurement.

Smart meters are used to obtain information such as voltage, current, power and others. However, users are not interested in technical data and need to have access to more common information as "how much money is being spent by a particular appliance". Thus, in our proposal it is possible to clearly visualize how much each device consumes and easily understand the consumption of electric energy.

Even with the technological advance of smart meters and the use of the Home Area Network (HAN), which is a type of Local Area Network (LAN) to facilitate communication between smart meters and home appliances this technology is not very accessible to the consumer because it is a complex system, difficult to use and presents high prices for the consumer ${ }^{4}$.

To meet this gap, the Home Energy Monitors were developed to provide real-time information about the hourly cost of the electrical energy consumption of the equipment under analysis, which are also easy to use and at more affordable prices. Currently there are many models available for purchase with prices that vary according to their functionalities. In addition, they are portable, simpler and cheaper than smart meters, but they do not replace them.

The prototype that measures the consumption of electric energy developed differs in some points from the others existing in the market. Some systems are plug-in type. These models are plugged between the power supply socket and the unit of measurement. They provide consumption only of a single device. However, there is the need to have the consumption of the entire residence, visually, throughout the day. This function is not offered in this type of system, nor the consumption data in monetary form. Its interface is unfriendly. Other systems have several features, and these are the devices we use as a model.

The developed prototype contemplates all the functionalities of the systems present in the study, focusing mainly on cost reduction, data transmission via Bluetooth and the use of more affordable electronic components.

\section{Purpose}

The promotion of energy efficiency encompasses the optimization of the transformations, transportation and use of energy resources, from their primary sources to their utilization. As basic assumptions, the maintenance of the conditions of comfort, safety and productivity of the users is adopted. These points contribute to the improvement of the quality of energy services and to the reduction of environmental impacts ${ }^{5}$.

The importance of energy efficiency actions in countries demonstrates the need for efficient use of existing energy. This action reduces the need for new investments in the plant and also reduces the cost of production and consequently the end use of energy. Energy efficiency tends to reduce losses in energy distribution and at the same time makes energy consumption more efficient, postponing the need to increase installed capacity and the need for new investments.

Intelligent metering can help reduce waste in the residential sector. On order for this to be possible, it is necessary that consumers have easy access to the available technologies, with the monitoring of the individual consumption of each electric device in their residence showing in monetary form how much each element consumes in a determined range of time.

The quest to combine growth with the efficient use of energy has strengthened two of the main strategies currently available: generation with renewable energy sources and energy management.

Energy efficiency appears as a much cheaper and more efficient alternative. Saving natural resources by reducing waste reduces production costs. The use of strategies that 
promote the increase of energy efficiency depends on guidelines and devices that sensitize the consumer agents.

The objective of this project was to propose and develop a prototype that performs the measurement of the real time energy consumption of residential equipment or a particular circuit. The block diagram of Figure 1 illustrates the elements of the system with their respective interconnections.

The prototype consists of two blocks, a block consisting of a current sensor that will be connected to the equipment to be analyzed [1] (a household appliance), a non-invasive current sensor [2], Arduino microcontroller [3] Display [4] which will be the hardware interface, to be developed. The microcontroller has a USB port [7] that will be the input on the Arduino. The second block will be software [5] that will be developed and used to display the results. This software receives the data through a wireless communication interface [6] connected to the computer [5].

The prototype of the energy meter was constructed to analyze the value of current and voltage considering a single phase circuit, and through this data it is possible to obtain the consumed power of the connected equipment in the system.

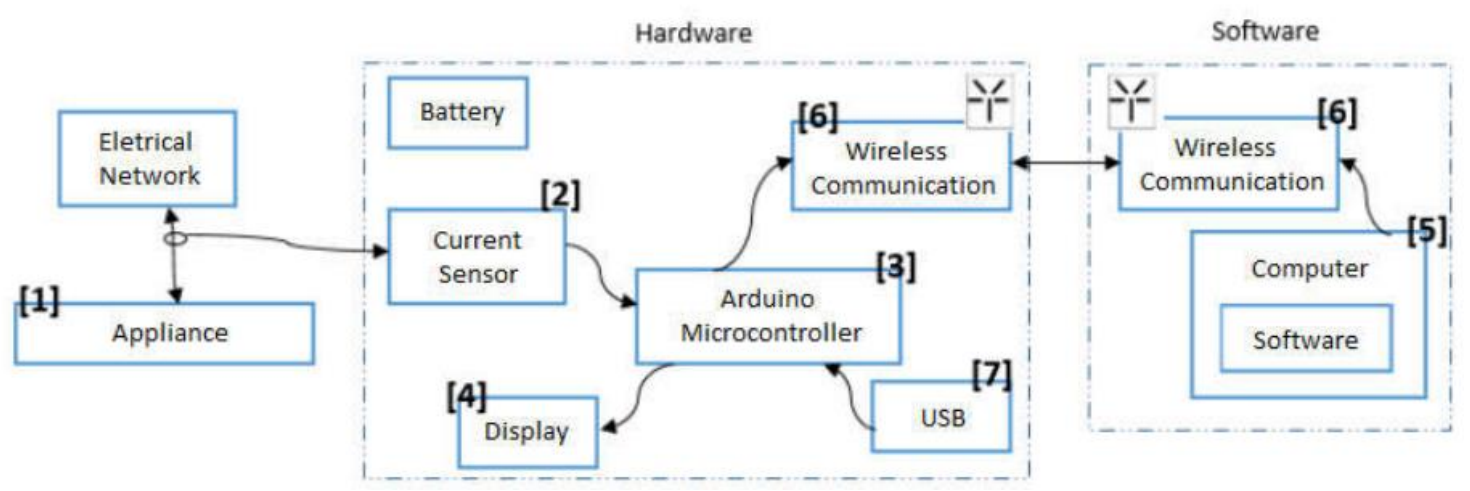

Figure 1- Project Blocks Diagram.

The energy consumed by an appliance at a certain time is then determined based on this value.

In this project, a non-invasive current meter was used, that is, to measure the current of the circuit it is not necessary to make any changes in it. It behaves as an ammeter and it is only necessary to open the sensor and wrap the wire of the equipment to be measured. For the measurement to be more precise it is necessary that only one wire is wrapped in the sensor. Otherwise you can have incorrect values or zero.

For the assembly of the hardware an MDF board was used to fix the peripherals. The peripherals are: a line filter (1) to connect the equipment, a 9V battery (2) to power the Arduino, a printed circuit board (3), an Arduino (4), a current sensor (5), which must be wrapped in the cable of the equipment to be measured and the AC-AC adapter (6). Figure 2 displays the final assembly of the prototype. 


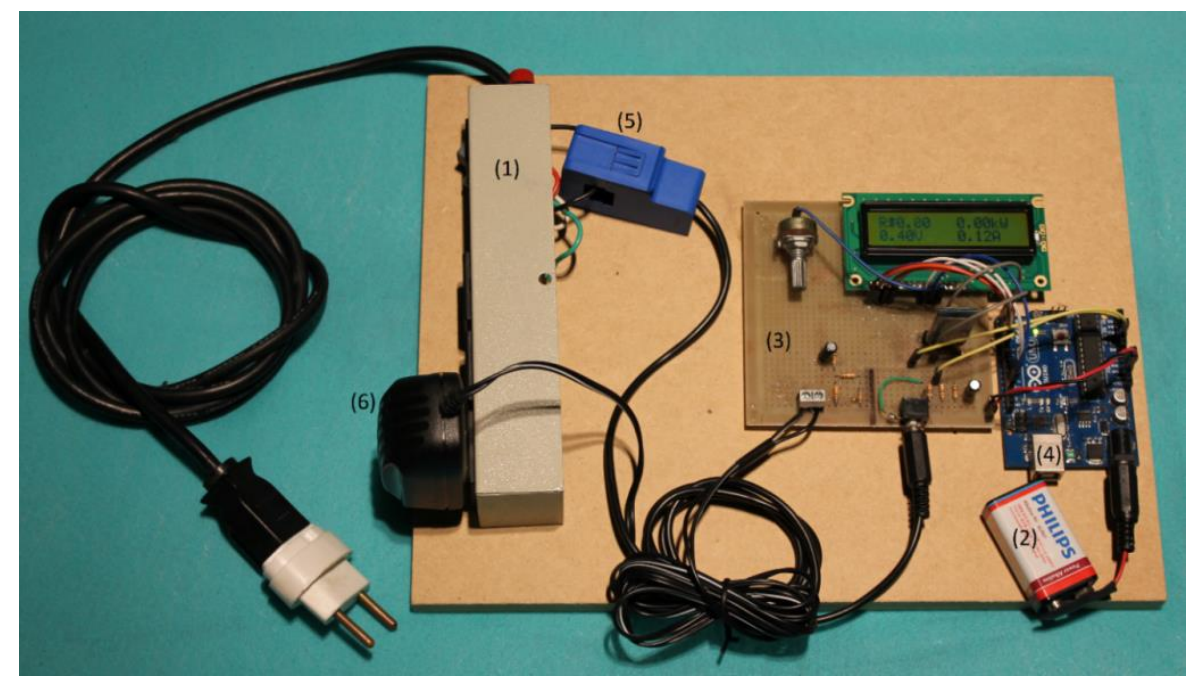

Figure 2 - Final Assembly of the Prototype.

For the calibration of the prototype, a three-phase electronic "SAGA 1000" meter and a variable resistive load, both supplied by COPEL, shown in Figure 3, were used. With this variable load connected in the network it was possible to vary the current from 0 to 50 Amperes. Through the calibrated energy meter a series of samples were collected, varying the current from 1 to $35 \mathrm{~A}$ with an increase of $2 \mathrm{~A}$ per sample.

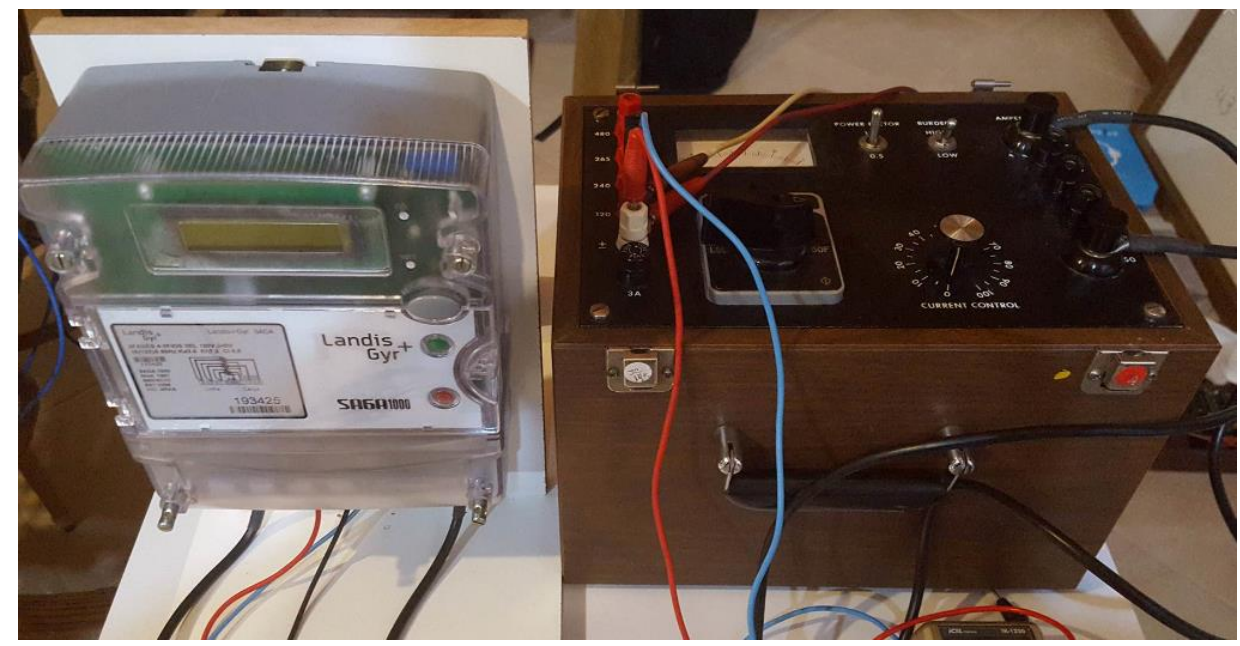

Figure 3 - The electronic Meter and Variable Resistive Load.

In order to carry out the calibration, we related the data provided by the calibrated equipment with that of the prototype, so the proper adjustments were made in the prototype programming. The results obtained were stored in an Excel table.

\section{RESULTS AND DISCUSSION}

In order to establish the actual performance characteristics of the proposed meter, some test conditions were determined and its results were evaluated in terms of percentage error, comparing the prototype to a commercial electric power register. The obtained error values were also compared to the standards of NBR 14519, which deals with the specification of electronic meters of electric energy.

In order to verify if the results obtained in the prototype were correct, a series of measurements were made in different equipment of residential use. The objective was 
to compare the values found in the prototype with values obtained by the certified and calibrated energy meter provided by COPEL, from Landys Gyr manufacturer, model SAGA 1000. Table 1 shows the values obtained in the consumption measurements of a passage heater.

Table 1- Values Obtained From the Electric Heater.

\begin{tabular}{rrrrrrrrr}
\hline \multicolumn{7}{c}{ Eletric Heater } \\
\hline $\begin{array}{c}\text { Current (A) } \\
1000\end{array}$ & Prototype & \multicolumn{1}{c}{ Error } & $\begin{array}{c}\text { SAGA } \\
1000\end{array}$ & Prototype & Error & $\begin{array}{c}\text { SAGA } \\
1000\end{array}$ & Prototype & Error \\
\hline 7,91 & 7,68 & $2,91 \%$ & 127 & 129,45 & $1,93 \%$ & 1004,57 & 994,176 & $1,03 \%$ \\
\hline 7,9 & 7,68 & $2,78 \%$ & 127 & 127,54 & $0,43 \%$ & 1003,3 & 979,507 & $2,37 \%$ \\
\hline 7,87 & 7,62 & $3,18 \%$ & 127 & 127,64 & $0,50 \%$ & 999,49 & 972,617 & $2,69 \%$ \\
\hline 7,87 & 7,69 & $2,29 \%$ & 127 & 127,19 & $0,15 \%$ & 999,49 & 978,091 & $2,14 \%$ \\
\hline 7,87 & 7,7 & $2,16 \%$ & 127 & 128,32 & $1,04 \%$ & 999,49 & 988,064 & $1,14 \%$ \\
\hline 7,87 & 7,68 & $2,41 \%$ & 127 & 129,71 & $2,13 \%$ & 999,49 & 996,173 & $0,33 \%$ \\
\hline 7,87 & 7,67 & $2,54 \%$ & 127 & 128,58 & $1,24 \%$ & 999,49 & 986,209 & $1,33 \%$ \\
\hline 7,87 & 7,68 & $2,41 \%$ & 127 & 127,61 & $0,48 \%$ & 999,49 & 980,045 & $1,95 \%$ \\
\hline 7,87 & 7,69 & $2,29 \%$ & 127 & 129,05 & $1,61 \%$ & 999,49 & 992,395 & $0,71 \%$ \\
\hline 7,87 & 7,68 & $2,41 \%$ & 127 & 129,08 & $1,64 \%$ & 999,49 & 991,334 & $0,82 \%$ \\
\hline 7,87 & 7,68 & $2,41 \%$ & 127 & 129,59 & $2,04 \%$ & 999,49 & 995,251 & $0,42 \%$ \\
\hline
\end{tabular}

The developed meter presented a satisfactory result in the tests, based on commercial equipment, where it can be observed that the values of voltage and current measured by the module were very close to those observed in the SAGA 1000. The error rate was $3.1 \%$, on average and this value was acceptable. However, the studies must continue so that this measurement error can be reduced.

The solution adopted, with the non-invasive current sensor for current detection and the Bluetooth module for communication, was presented as the lowest cost. This prototype presented a reliable performance. It has a low implementation cost and ease of use. And it also provides easy visualization of the results through an application, having achieved all the main objectives of the proposed project.

Specific objectives were successfully met. The Arduino microcontroller worked as expected and through it, from the current sensor and the AC-AC adapter, it was possible to efficiently measure the electric power consumption.

The measurement and data collection modules have been completed and tested. The project presents a vision focused on sustainability, enabling the common user to control their spending with energy.

\section{CONCLUSIONS}

The main objective in which this prototype was developed is the need to improve the use of energy offered to consumers, postponing the need to make new investments to increase the already installed energy capacity. We realized through the study presented here the need to approach residential consumers, who have a significant share in total consumption, and the efficient use of energy and for this reason, the prototype was developed.

The prototype facilitates the visualization of the data and allows a better monitoring of the energy consumption. The components used to make the system met the expected objectives, aiming at the quality and low cost of implementation. The tests in which we 
submitted the prototype, using certified and homologated equipment by COPEL, proved its good performance.

The price obtained for the commercialization of this system is of $\mathrm{R} \$ 108.00$. With this we conclude that it is possible to sensitize the residential consumer through the system, which presents a low cost in relation to its benefit and thus increases the efficient use of energy.

Plans for the future include visual improvements in the prototype so that it can be considered a product and then commercialized. Another future proposal would be to create a database in the application so that it can be made available and from it to create consumption targets for the consumer. It would also be interesting to increase more current sensors for the individual calculation of the consumption of various loads and also the intervention in the circuit, i.e. to connect and disconnect loads through the wireless network.

\section{REFERENCES}

1. Monika Menkes. Eficiência Energética, Póliticas Públicas e Sustentabilidade. 2004. 277 f. Tese de Doutorado - Universidade de Brasília, Centro de Desenvolvimento Sustentável, 2004.

2. Empresa de Pesquisa Energética, Balanço Energético. 2016. Disponível em <https://ben.epe.gov.br >. Acesso 24/09/16.

3. Companhia Paranaense de Energia. História da energia elétrica. 2015. Disponível em <http://www.copel.com/hpcopel/root/index.jsp> Curitiba: COPEL, 2015. Acesso em: $06 / 2015$.

4. Erez Bem Tovi. "ITU G.hn - Broadband Home Networking". In Berger, Lars T.; Schwager, Andreas; Pagani, Pascal; Schneider, Daniel M. MIMO Power Line Communications: Narrow and Broadband Standards, EMC, and Advanced Processing. Devices, Circuits, and Systems. CRC Press. 2014.

5. Ministério do Meio Ambiente. Eficiência Energética e Conservação de Energia. 2015. Disponível em http://www.mma.gov.br/clima/energia/eficiencia- energetica 